Check for updates

Cite this: RSC Adv., 2017, 7, 23197

Received 13th February 2017

Accepted 10th April 2017

DOI: $10.1039 / c 7 r a 01793 f$

rsc.li/rsc-advances

\section{Organoboron copolymers containing thienothiophene and selenophenothiophene analogues: optical, electrochemical and fluoride sensing properties $\uparrow$}

\begin{abstract}
Gulsen Turkoglu, ${ }^{a}$ M. Emin Cinar (D) ab and Turan Ozturk (D) *ac
Conjugated donor-acceptor ( $D-A)$ copolymers possessing alternating fused bicyclic aromatic rings thieno [3,2-b]thiophene, selenopheno[3,2-b]thiophene, thieno[2,3-b]thiophene and selenopheno[2,3-b] thiophene as donors, thiophene as a $\pi$-conjugated bridge and mesitylboron as an acceptor were synthesized and characterized by spectroscopic methods. Large Stokes shifts of 96-166 nm were recorded and the solution quantum yields of the polymers were in the range of $5-18 \%$. Their ionization potentials and electron affinities were investigated by cyclic voltammetry. Optical band gaps varied between 2.26 and $2.78 \mathrm{eV}$. (TD)-DFT studies were performed to unveil their electronic structures, KohnSham orbitals and electronic transitions. Absorption and emission measurements revealed that these polymers have high sensitivity to fluoride anions, among which the polymer possessing crossconjugated thienothiophene units had the best sensing properties supported by orbital composition analysis with Mulliken partition. Thus, copolymers P1-P4 could be used as colorimetric and fluorescent sensors for small fluoride anions.
\end{abstract}

\section{Introduction}

Like thiophenes, selenophenes are categorized in the class of chalcogenophenes. ${ }^{1}$ Fused selenophenes have been the focus of scientists owing to their promising use in optoelectronic materials. ${ }^{2}$ In spite of the extensive laboratory work devoted to the synthesis and investigation of organic thin film transistors (OTFTs), to the best of our knowledge, the properties of oligomeric fused selenium heterocycles and fused selenophene containing polymers have not been thoroughly explored, possibly due to lack of synthetic methodologies and their low solubilities. ${ }^{3}$ Replacement of sulphur with selenium enhances the optoelectronic properties, such as an increase of conductivity as observed with tetraselenafulvalene (TSF) with respect to tetrathiafulvalene (TTF) derivatives at room temperature. ${ }^{4}$ Moreover, polyselenophenes have higher conductivity and mobility which might be based on better p-orbital overlap in Se compounds. ${ }^{1,5}$ Furthermore, polyselenophenes have smaller band gaps according to both computational ${ }^{6}$ and experimental

${ }^{a}$ Department of Chemistry, Istanbul Technical University, Maslak, Istanbul 34469, Turkey.E-mail: ozturktur@itu.edu.tr

${ }^{b}$ Department Chemie-Biologie, OC1, Universität Siegen, Adolf-Reichwein-Str., 57068 Siegen, Germany

'Chemistry Group Laboratories, TUBITAK UME, PO Box 54, 41470, Gebze-Kocaeli, Turkey

$\dagger$ Electronic supplementary information (ESI) available. See DOI: 10.1039/c7ra01793f studies. ${ }^{7}$ In addition, organic materials having "Se" atom in their structures are supposed to have higher frontier molecular orbitals (FMO), i.e. lower oxidation and reduction potentials, and easier polarizability. Existence of intermolecular Se $\cdots \mathrm{Se}$ interactions in their structures leads to plausible inter-chain charge transfers, ${ }^{8}$ accepted as gorgeous properties for optoelectronics.

It is well known that fused thiophene containing polymers, as an active layer, provide high charge mobilities in field effect transistors (FET). ${ }^{9}$ Besides, fused rings afford a high degree of planarity and rigidity resulting in higher crystallinity and extended pi overlap. Additionally, they do not only hinder unfavourable chain folding but also diminish reorganization energy of the molecules, and make feasible intermolecular charge hopping, resulting in the increase of the mobility.

Heteroaromatic compounds with sulphur have been the one of the best candidates as electron-donating scaffolds for low band gap polymers. Their Se analogues afford high charge mobilities arisen from strong intermolecular interactions through Se atoms..$^{10}$ Exchange of sulphur with selenium, known as a less electronegative and more polarizable atom with respect to sulphur, affects the electronic and optical properties. ${ }^{11}$

The low band gap polymers can be successfully achieved through $\mathrm{D}-\pi-\mathrm{A}$ approach, which requires copolymerization of electron-rich donor and strong acceptor monomers. ${ }^{12}$ LUMO of the obtained polymers is predominantly located on the electron accepting unit, whereas HOMO is mainly placed on the donor 
material. In addition to the fused heteroaromatic systems with sulphur and/or selenium atoms, conjugated organic molecules and polymers containing three-coordinate boron have also drawn considerable attention owing to their convincing optoelectronic and sensor properties. ${ }^{13}$ As boron is an electron deficient atom, it has a strong electron acceptor character due to its empty $\mathrm{p}$ orbital. Its use in polymers having conjugated electron donor units has generated a new type of donoracceptor conjugated polymeric systems for material science. ${ }^{\mathbf{1 4}}$ The bulky mesityl group attached to the boron protects it from any nucleophilic attacks. Thus, boron containing compounds with vacant $\mathrm{p} \pi$ orbital can also be used as Lewis acids to coordinate Lewis bases, such as fluoride ions $\left(\mathrm{F}^{-}\right)$, leading to a remarkable colour and/or luminescence changes, which have been extensively exploited in chemical sensors. ${ }^{15}$

Herein, we report the synthesis, optical and electrochemical properties of four novels D- $\pi$-A copolymers P1-P4, possessing acceptor mesityl boron units and donor fused conjugated and cross conjugated selenophenothiophene heteroaromatic linkers. A detailed structure-property correlation suggests insights into the influence of linkers on the electronic structures and photophysical properties of organoboron polymers. Finally, all the copolymers have been successfully applied to detect fluoride anion $\left(\mathrm{F}^{-}\right)$in order to probe their sensing properties.

\section{Results and discussion}

\section{Synthesis of monomers and polymers}

The syntheses of the polymers P1-P4 are shown in Scheme 1. Dibrominated monomers 1-4 were synthesized according to the established methods. ${ }^{3 \boldsymbol{b}, \mathbf{1 6}-18}$ The precursors for the polymerizations, 2,5-di(thiophen-2-yl)selenopheno[3,2-b]thiophene (5), 2,5-di(thiophen-2-yl)selenopheno[2,3-b]thiophene (6), 2,5di(thiophen-2-yl)thieno[3,2-b]thiophene (7) and 2,5-di(thiophen-2-yl)thieno[2,3- $b]$ thiophene (8) were synthesized via a Suzuki coupling in moderate to good yields (40-72\%). Syntheses of the polymers were performed through the reactions of the monomers 5-8 with mesityldimethoxyborane (Scheme 1). Lithiation of the monomers with $n$-BuLi at $-78{ }^{\circ} \mathrm{C}$ was followed by addition of mestiyldimethoxyborane in THF at room temperature providing the polymers P1-P4. They were purified by precipitation from $n$-hexane leading to reddishorange (P1), yellow (P2), reddish-brown (P3) and orange (P4)

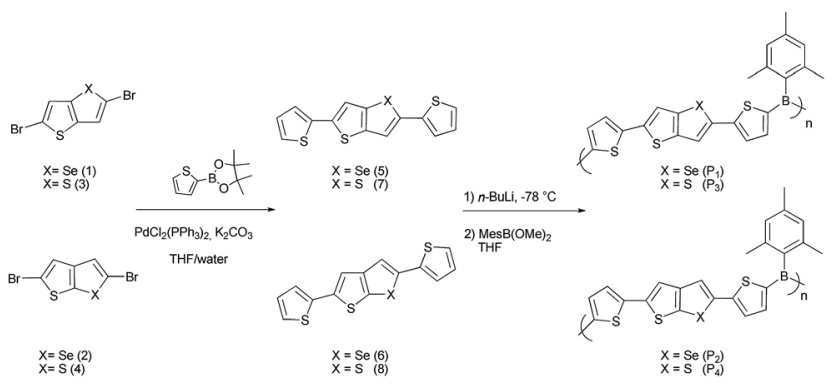

Scheme 1 Preparation of the polymers P1-P4. powdery solids in the yields of $39-50 \%$. The polymers were found to be stable to air and moisture that no special precaution was taken during the purification processes. The numberaverage molecular weights $\left(M_{\mathrm{n}}\right)$ of P1-P4 were determined using light scattering technique and found to be $97.9 \mathrm{kDa}, 11.2$ $\mathrm{kDa}, 40.5 \mathrm{kDa}$, and $40.7 \mathrm{kDa}$, respectively. As thermal gravimetric analysis (TGA) provides valuable information on thermal stability of materials, TGA analyses of the polymers P1-P4 were conducted, which indicated the relative thermal stability of P1 and $\mathbf{P} 3$ with respect to $\mathbf{P 2}$ and $\mathbf{P 4}$ (Fig. S7 $\dagger$ ). While main thermal decomposition steps of $\mathbf{P 1}$ and $\mathbf{P} \mathbf{3}$ was observed around 178 and $170{ }^{\circ} \mathrm{C}$, respectively, decompositions of $\mathbf{P} 2$ and $\mathbf{P 4}$ were recorded to be at lower temperatures ( 78 and $154{ }^{\circ} \mathrm{C}$, respectively). Lower molecular weight could be a reason for the lower decomposition temperature of the polymer $\mathbf{P 2}$.

\section{Photophysical properties}

The UV-Vis absorption spectra of the polymers in THF and spincoated thin-films were recorded (Fig. 1 and S8 in ESI $\dagger$ ) and therefrom obtained corresponding data are summarized in Table 1. The lowest energy absorptions were assigned to be localized $\pi-\pi *$ transitions with a strong intramolecular charge transfer (ICT) to boron acceptor. UV-Vis absorption maxima of both P1 and P3 polymers were significantly red-shifted implying that they had effective conjugation lengths with respect to P2 and P4. While the maxima were recorded for P1 and P3 to be 406 and $400 \mathrm{~nm}$, respectively, those were $362 \mathrm{~nm}$ for $\mathbf{P 2}$ and $348 \mathrm{~nm}$ for $\mathbf{P 4}$, which have cross-conjugated selenopheno[2,3- $b]$ thiophene and thieno[2,3-b]-thiophene, respectively (Fig. 1). This large hypsochromic shifts of $\mathbf{P 2}(44 \mathrm{~nm})$ and $\mathbf{P 4}(52 \mathrm{~nm})$ are consistent with a diminished effective conjugation length compared to P1 and P3. Furthermore, the comparatively low absorptions of $\mathbf{P 2}$ and $\mathbf{P 4}$ could be connected to the poor electronic couplings of cross-conjugated donors and mesitylboron acceptor in the polymer chain. In addition, the absorption maxima obtained from thin-films of P1-P4 were about 6 to $12 \mathrm{~nm}$ red-shifted compared to solution state, supporting well organized intermolecular packings and sulfur-sulfur interactions in solid states in solid states. ${ }^{19}$ Optical HOMO-LUMO gaps of the polymers were determined from the onsets of UV-Vis absorption spectra in solution state to be $2.26 \mathrm{eV}$ for $\mathbf{P 1}$ as the smallest one, and 2.60, 2.52 and $2.78 \mathrm{eV}$ for P2-P4, respectively. The smallest band gap of $\mathbf{P 1}$ mainly emerges from the strong $\mathrm{D}-\mathrm{A}$ interaction between the electron rich selenopheno[3,2- $b]$ thiophene, more efficiently increasing the HOMO level than the

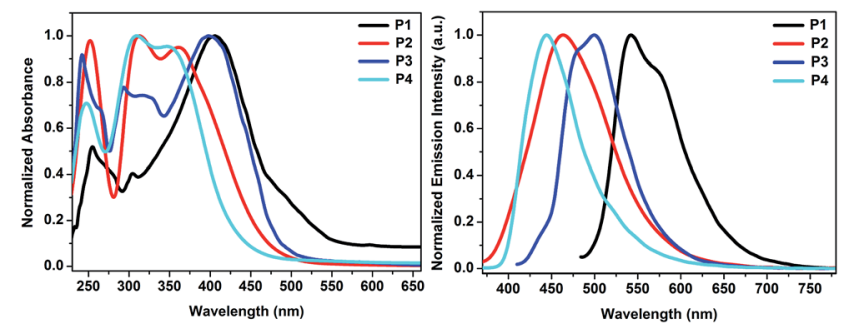

Fig. 1 UV-Vis (left) and emission (right) spectra of P1-P4 in THF. 
Table 1 Photophysical and electrochemical properties of polymers P1-P4

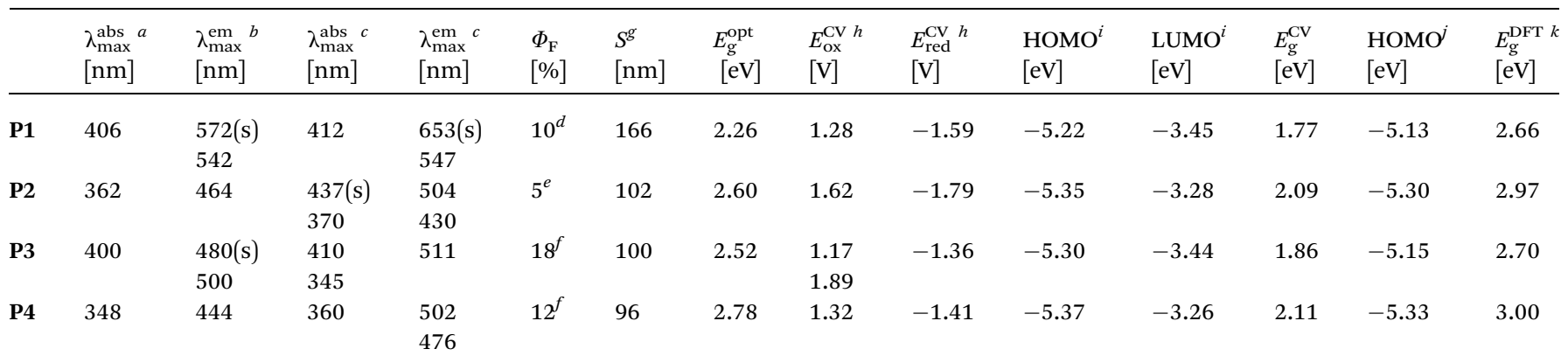

${ }^{a}$ Only longest wavelength absorption in THF. ${ }^{b}$ Emission in THF. ${ }^{c}$ Absorption and emission maxima of the polymer films spin coated on glass. ${ }^{d}$ Using rodhamine $6 \mathrm{G}$ as a standard in ethanol. ${ }^{e}$ Anthracene as a standard in cyclohexane. ${ }^{f}$ Coumarin 1 as a standard in ethanol. ${ }^{g}$ Stokes

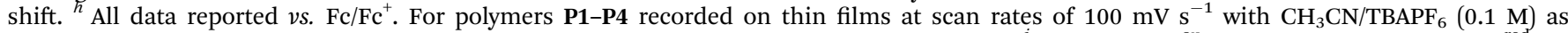
supporting electrolyte; $E_{\mathrm{Ox}}$ and $E_{\mathrm{red}}$ were estimated from the oxidation and reduction peaks. ${ }^{i} \mathrm{HOMO}=-E_{\mathrm{onset}}^{\mathrm{ox}}+4.40(\mathrm{eV}), \mathrm{LUMO}=-E_{\mathrm{Onset}}^{\text {red }}+$ $4.40(\mathrm{eV}) .{ }^{J}$ At (PCM:THF)B3LYP/6-31G(d) level. ${ }^{k}$ From (CPCM:THF)-CAM-TD-B3LYP/6-311++G(d,p)//B3LYP/6-31G(d) level computations.

corresponding conjugated sulphur containing thieno[3,2- $b]$ thiophene, and the electron poor mesitylboron units, diminishing the LUMO level and prompting strong ICT. ${ }^{13 d}$

The fluorescence spectra of the solutions, having the same concentration used for the UV-Vis measurements and thin films, were recorded (Fig. 1, S8, $\dagger$ and Table 1). While a strong yellow-green emission at $542 \mathrm{~nm}$ with a shoulder peak at around $572 \mathrm{~nm}$ was recorded for P1, polymer $\mathbf{P 3}$ emitted a green colour with $\lambda_{\text {em }}$ maximum of $500 \mathrm{~nm}$, which is about $42 \mathrm{~nm}$ blue shifted compared to that of $\mathbf{P 1}$ pointing out the more effective conjugation and charge transfer in P1. Presence of crossconjugated selenopheno[2,3- $b]$ thiophene and thieno[2,3- $b]$ thiophene in the main backbones of P2 and P4 caused a significant blue-shift with respect to P1 and P3. While P2 exhibited a deep-blue emission at $464 \mathrm{~nm}, \mathbf{P 4}$ gave a blue-violet emission at around $444 \mathrm{~nm}$. Thus, the photophysical properties of these emitters are strongly affected primarily by the $\pi$ conjugation length and then with the presence of "Se" atom in the ring. Absorption spectra of $\mathbf{P 2}$ and $\mathbf{P 4}$ had two maxima above $300 \mathrm{~nm}$. While low energy absorption bands arose from $\pi-\pi *$ transitions, high energy absorption bands were trigged by charge transfer to mesitylboron unit. The fluorescence quantum yields $\left(\Phi_{\mathrm{F}}\right)$ of both copolymers were measured in THF and found to be 0.18 for $\mathbf{P} 3$ and 0.12 for $\mathbf{P 4}$, whereas the other polymers P1 and P2 exhibited slightly lower quantum yields of 0.10 and 0.05 , respectively, due to higher rate of nonradiative decays emerging from high degree of stabilization of charge transfer state, by means of that making vicinity of this state to ground charge transfer states. Moreover, P1 and P3 had the same longest absorption wavelengths, the emission of P1 was found to be much longer than P3, which had the largest Stokes shift of $166 \mathrm{~nm}$. While the polymers P1 and P2, having selenophenothiophene units, exhibited the Stokes shift of 166 and $102 \mathrm{~nm}$, respectively, those of the other polymers P3 and P4, possessing thienothiophene units, had the Stokes shits of 100 and $96 \mathrm{~nm}$, respectively. These results clearly indicated that cross-conjugated ring of selenophenothiophene, i.e. selenopheno $[3,2-b]$ thiophene, is more effective in generating red shift in fluorescence, which is obviously due to a better contribution of big selenium atom to the available proper conjugation compare with sulphur atom.

The solid state fluorescence of P1-P4 showed an intense green fluorescence with the maxima of 547, 504, 511, and $502 \mathrm{~nm}$, respectively (Fig. S8, $\uparrow$ Table 1). Such a clear red-shift from 5 to $66 \mathrm{~nm}$ in comparison to the solution state could be attributed to boron acceptor and rigid fused aromatic donor core units having better interactions in solid state.

\section{Electrochemical properties}

The redox properties of all the polymers were determined by cyclic voltammetry on thin films. The CV diagrams of the polymers P1-P4 are depicted in Fig. 2 and electrochemical results are listed in Table 1 . While the oxidation processes were irreversible for P1, P2 and P4, two quasi-reversible characteristics $\left(E_{\mathrm{ox}}=+1.17\right.$ and $+1.89 \mathrm{~V}$, vs. $\left.\mathrm{Fc} / \mathrm{Fc}^{+}\right)$were recorded for $\mathbf{P} 3$, the first oxidation process of which was found to occur at the lowest potential among the four polymers. Slightly lower oxidation potential of $\mathbf{P 1}\left(E_{\mathrm{ox}}=+1.28 \mathrm{~V}\right)$, having a crossconjugated selenophenothiophene unit, than P2 $(+1.62 \mathrm{~V})$ indicated a low laying HOMO of P2 compared to P1. The same trend was observed with $\mathbf{P 3}$ and P4. The oxidation of $\mathbf{P 4}(+1.32$ $\mathrm{V})$, possessing a cross-conjugated thienothiophene, was found to be more difficult than $\mathbf{P 3}$. The reason for the difference could
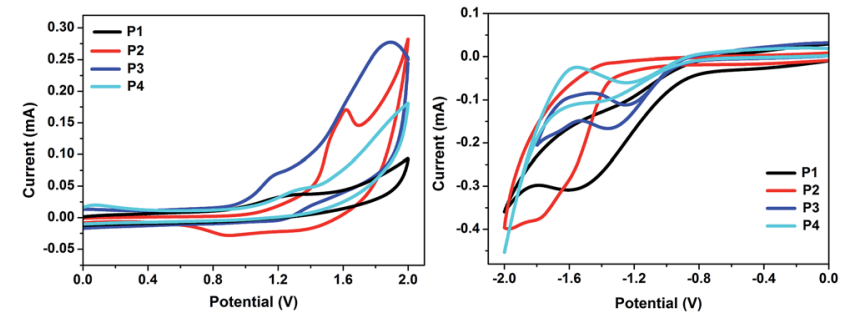

Fig. 2 Cyclic voltammograms of the polymers P1-P4 on glassy carbon disk electrode in acetonitrile, $0.1 \mathrm{M} \mathrm{Bu}_{4} \mathrm{NPF}_{6}, 100 \mathrm{mV} \mathrm{s}^{-1}$ scan rate, vs. $\mathrm{Fc} / \mathrm{Fc}^{+}$. 
be explained not only with the presence of the different donor units in the polymer back-bones but also with the structures of the fused rings.

All the polymers displayed irreversible reduction peaks in the CV diagrams, which is possibly due to the known relaxation effects generating hysteresis phenomena (Fig. 2). The reduction potentials of P1 and P2 were recorded to be -1.59 and $-1.79 \mathrm{~V}$, whereas those of $\mathbf{P 3}$ and $\mathbf{P 4}$ were measured as -1.36 and $-1.41 \mathrm{~V}$, respectively, indicating a more difficult reduction in the case of P1 and P2 possessing electron rich and more polarizable Se atoms with respect to P3 and P4 having more electronegative and less polarizable $\mathrm{S}$ atoms. In addition, compared to P1 and P2, the boron-copolymers P3 and P4 showed more positive shifts in their first reduction potentials, supporting improved electron-accepting ability.

From the electrochemical data, the HOMO and LUMO energy levels and there from calculated energy gap of P1-P4 are listed in Table 1. The HOMOs of P1-P4 were found to be in the range of -5.22 to $-5.37 \mathrm{eV}$, while LUMO energy levels were obtained at -3.45 to $-3.26 \mathrm{eV}$. The HOMO energy levels of P1 and $\mathbf{P 2}$ are lower than the corresponding $\mathrm{S}$ containing crossconjugated P3 and P4 pointing out a better stability of P2 and P4 against oxidative doping. The calculated electrochemical HOMO-LUMO gaps of selenophenothiophene derivatives (1.77 eV for P1 and 2.09 eV for P2) are considerably smaller than those of corresponding thienothiophene analogues $(1.86 \mathrm{eV}$ for P3 and 2.11 eV for P4).

\section{Fluoride sensing properties}

Presence of electron-deficient boron centres could be a good advantage for anion bindings such as fluorides and cyanides. ${ }^{15 c, 15 e, 15 g, 20}$ Triarylboranes have been widely studied as chemo-sensors for fluoride anions with high selectivity and sensitivity. ${ }^{21}$ Complexation of boron with anions typically leads to a distinct change in the photophysical properties, and polymeric species are particularly interesting because of their potential for reciprocal interactions with different binding sites. ${ }^{15 b, 15 g, 22}$ Thus, tetrabutylammonium fluoride (TBAF) as
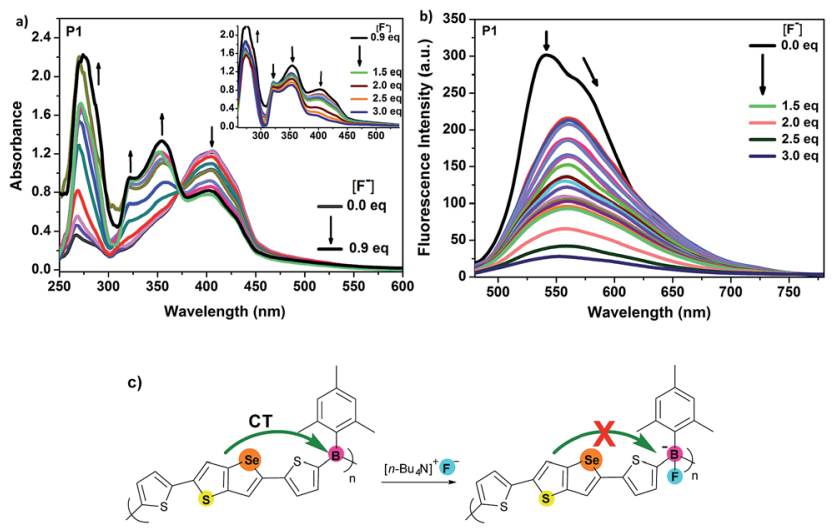

Fig. 3 (a) Absorption spectra and (b) emission spectra ( $\lambda_{\text {exc }}=470 \mathrm{~nm}$ ) of P1 ( $1 \times 10^{-4} \mathrm{M}$ based on boron sites) in THF in the presence of various amounts of TBAF. (c) Pictorial view of interruption of charge transfer (CT) by fluoride binding. a fluoride source was gradually added to a THF solution of each polymer and the response of P1-P4 to fluoride anions was investigated by UV-Vis absorption and fluorescence spectroscopy. Titration of organoborane polymers P1-P4 with fluoride ion displayed an interesting binding process of fluoride ion to boron atom in the absorption spectra. Upon addition of less than 1.0 equiv. of TBAF to the polymer P1, while the absorption at $406 \mathrm{~nm}$ started to decrease, new bands gradually appeared in the high-energy region at 267, 322 and $354 \mathrm{~nm}$, intensities of which enhanced upon continuing the addition of TBAF (Fig. 3a). An isosbestic point at $373 \mathrm{~nm}$ was observed. On the other hand, when more than 1.0 equiv. of TBAF was added, intensities of the new absorption bands started to decrease and the absorption band at $406 \mathrm{~nm}$, which already decreased upon addition of TBAF, almost disappeared along with the disappearance of the isosbestic point. This process was reflected in a colour change of the solution from yellow to complete colourless, which allowed a naked-eye detection of fluoride anion. Decrease of the band at $406 \mathrm{~nm}$ and appearance of the new bands at 267, 322 and $354 \mathrm{~nm}$ may indicate the interaction of boron atoms with fluoride ions and interruption of electron flow to boron, which causes shortening of the conjugation and lowering of the absorption at $406 \mathrm{~nm}$. Further addition of TBAF, i.e. above 1.0 equiv., may result in the quenching of the polymer and decrease of absorptions even at 267, 322 and $354 \mathrm{~nm}$.

Fig. $3 \mathrm{~b}$ shows the change in fluorescence spectrum of P1 upon addition of various concentrations of TBAF. After the addition of first 0.05 equiv. of TBAF, a sharp decrease of emission intensity at $542 \mathrm{~nm}$ with a shoulder at $572 \mathrm{~nm}$ was observed with an appearance of a new band with lower intensity at $560 \mathrm{~nm}$. When reached the addition of 3.0 equiv. of TBAF, almost a complete quenching took place. Thus, P1 works as a "turn-off" sensor for fluoride ion. This result is attributable to the apparent amplified quenching effect, which has also been described for other organoborane polymers, ${ }^{15 b, 22 a-f}$ involving the efficient energy transfer to lower energy charge transfer states which are generated by binding of fluoride anion to boron.

Next, fluoride sensing properties of $\mathbf{P 3}$ were examined (Fig. S9a†). Similarly, upon addition of TBAF, the characteristic intense charge-transfer absorption band at $400 \mathrm{~nm}$ steadily decreased, while the absorption maximum at 242, 329 and $293 \mathrm{~nm}$ appeared and further addition up to 0.7 equiv. made them intense bands. An isosbestic point at $350 \mathrm{~nm}$ was obtained at this stage. Continuing the addition from 0.7 to 2.4 equiv. caused all the absorption bands gradually decrease, except the band at $242 \mathrm{~nm}$, which slightly increased, and a new weak band at $370 \mathrm{~nm}$ appeared. Colour of the solution turned to colourless from yellow. Furthermore, the emission intensity of P3 was also quenched in this process (Fig. S9b $\dagger$ ).

The stepwise addition of TBAF resulted in a steady decrease of the broad emission band between 375-600 nm, which was almost completely quenched with 3.0 equiv. of TBAF; hence it is also a "turn-off" sensor for fluoride ion. Quenching of fluorescence intensity was observed to be more effective with the polymer P3 (78\%) compare with the polymer P1 (69\%) at the addition of the same amount of TBAF (1.5 equiv.). Absorption and emission changes of the polymers (P1 and P3) clearly 

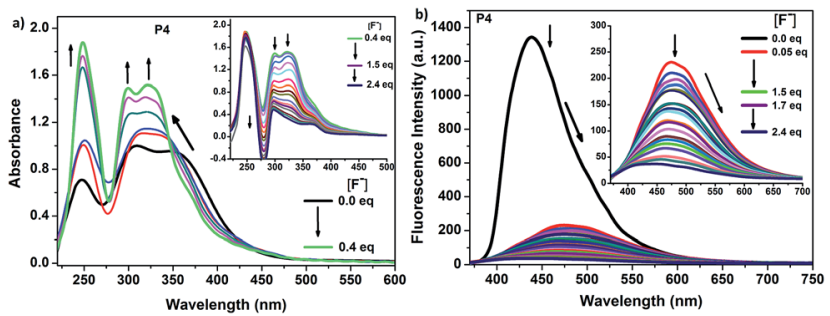

Fig. 4 (a) Absorption spectra and (b) emission spectra $\left(\lambda_{\text {exc }}=350 \mathrm{~nm}\right.$ ) of P4 ( $1 \times 10^{-5} \mathrm{M}$ based on boron sites) in THF in the presence of various amounts of TBAF.

indicated the disruption of the $\pi$-conjugation through the boron empty orbital by the formation of the corresponding fluoroborate in the polymer chain.

Considering the specific interactions between $\mathrm{F}^{-}$and the boron centres of $\mathbf{P 1}$ and $\mathbf{P 3}$, the response of $\mathbf{P 2}$ and $\mathbf{P 4}$ to $\mathrm{F}^{-}$was also investigated through absorption and fluorescence spectra (Fig. S10 $\dagger$ and 4). With the initial addition of fluoride ions up to 0.6 equiv. the main absorption peaks of $\mathbf{P 2}$ at 252,312 and $364 \mathrm{~nm}$ increased dramatically, while the absorption peaks at 312 and $364 \mathrm{~nm}$ were slightly blue shifted by 26 and $12 \mathrm{~nm}$, respectively. When the addition of the ion was continued from 0.6 to 2.4 equiv., all the bands were gradually decreased as a result of coordination of the fluoride ion to the empty p orbital of the boron atom. A similar tendency was observed with the polymer $\mathbf{P 4}$ in absorption spectra upon addition of fluoride anion (Fig. 4a). Moreover, in both $\mathbf{P 2}$ and $\mathbf{P 4}$, a colour change of the solution from yellow to complete colourless was observed. In the fluorescence spectra, although initially $\mathbf{P 2}$ exhibited a deep blue ICT emission at $464 \mathrm{~nm}$, intensity of the emission was steadily decreased resulting in $60 \%$ of fluorescence quenching efficiency with the increase of fluoride ion concentration and a violet-blue emission peak at $431 \mathrm{~nm}$ emerged (Fig. S10†). This indicated the donor-acceptor interaction between cross conjugated selenophenothiophene and boron has stopped. In contrast to the behaviour of $\mathbf{P 2}$, the emission of P4 at $444 \mathrm{~nm}$ was almost completely quenched and a red-shifted band at $480 \mathrm{~nm}$, having weak intensity at $475 \mathrm{~nm}$ was developed with an addition of small amount of fluoride ion ( 0.05 equiv.) (Fig. 4b). It was disappeared with further addition of TBAF. That is, addition of only 0.05 equiv. of TBAF led to about $82 \%$ fluorescence quenching of $\mathbf{P 4}$ and the emission intensity was almost completely quenched $c a$. 94\% with 1.5 equiv. of TBAF. Stern-Volmer plots shown in Fig. S11 $\uparrow$ for both $\mathbf{P 1}$ and $\mathbf{P 2}$ are nearly identical, indicating that both molecules have a similar affinity toward fluoride ion in fluorescence quenching mechanism. On the other hand, the polymers $\mathbf{P 3}$ and $\mathbf{P 4}$ had higher sensitivities toward fluoride ions compare with P1 and P2. Thus, polarizability difference of Se and S atoms and their orientation in the ring could be affecting the sensing power of the whole material. Comparison of the both systems, i.e. "Se" $(\mathbf{P 1}, \mathbf{P 2})$ and "S" (P3, P4), indicated that as Se is a better electron donor compare with $\mathrm{S}$ atom, it provides more electrons to the empty orbital of boron making the material less sensitive toward fluoride ions. Thus, the systems containing Se atoms are less sensitive accepting fluoride ions. Concerning the best sensitivity of $\mathbf{P 4}$, it has the least electron donation among the four polymers due to both having " $\mathrm{S}$ " atom instead of "Se" and its cross-conjugated structure.

\section{Computation}

The properties of the polymers were investigated further by performing density functional theory (DFT) calculations on monomers (M) and segments of polymers (S), possessing mesitylboron acceptor between thienothiophene (TT) and selenophenothiophene (SeT) donor units (Fig. 5). Geometry optimizations of their $\mathrm{S}_{0}$ and $\mathrm{S}_{1}$ states were realized without any symmetry constraints by means of Gaussian 09 package program. ${ }^{23}$ B3LYP ${ }^{24}$ method with $6-31 \mathrm{G}(\mathrm{d})$ basis set was chosen because of its good performance in the estimation of structures and properties of optoelectronic compounds. ${ }^{25}$ Solvent effect (THF) was included by using polarizable continuum model (PCM) ${ }^{26}$ Analysis of the harmonic vibrational frequencies using analytical second derivatives was performed to confirm the minima. Orbital composition analysis with Mulliken partition was carried out using Multiwfn program (a multifunctional wavefunction analyser). ${ }^{27}$ TD-DFT calculations with solvent effect $(\mathrm{CPCM})^{28}$ were conducted on polymer segments at coulomb-attenuating density functional theory (CAM-TDB3LYP $)^{29}$ level with 6-311++G(d,p) basis set to obtain the lowest singlet-singlet vertical excitations owing to the good performance of CAM-B3LYP in the calculations of excitation energies. ${ }^{30}$ Absorption bands were collected for singlets with $\mathrm{N}$ states of 50. While visualization of MOs with an isosurface value of 0.04 au was accomplished with GaussView 5.0, absorption and emission spectra were produced with GaussSum 3.0. ${ }^{31}$

Computations performed on the monomers depicted that TT and SeT units attached to the mesityl boron are almost planar to the boron plane with a dihedral angle of less than $10^{\circ}$, whereas the mesityl group attached to boron atom stayed vertical with respect to TT and SeT groups $\left(>60^{\circ}\right)$ (Fig. 5). The localized HOMOs are observed on TT and SeT groups of all the molecules, spreading marginally over the thiophene substituents. On the other hand, the LUMOs of the molecules are entirely located on boron atoms with slight contributions of TT and SeT units. Therefore, TT and SeT play as electron rich groups and mesityl boron as an electron poor unit. In the case of monomers M2 and M4 with cross-conjugated systems, LUMO orbitals are spread over only half of the TT and SeT units. MOs undoubtedly demonstrate an ICT between donor and acceptor units. The presence of nodes on electron poor boron atoms in HOMOs results in the charge density separation and consequently hampers the delocalization of HOMOs over all the whole system witnessed with the constructed HOMO surfaces for S1-S4.

The predicted HOMO energy levels of $-5.13,-5.30,-5.15$, and -5.33 for S1-S4 are matching well with those of P1-P4 (Table 1), respectively, emphasizing the increase of HOMO levels with incorporation of Se atoms in P1 and $\mathbf{P 3}$ compared to $\mathbf{P 2}$ and P4. This phenomenon was reflected to HOMO-LUMO gaps. That is, $E_{\text {gap }}$ values of $2.66,2.97,2.70$, and $3.00 \mathrm{eV}$ were slightly overestimated at TD-TDFT level of theory (Table 1), but 


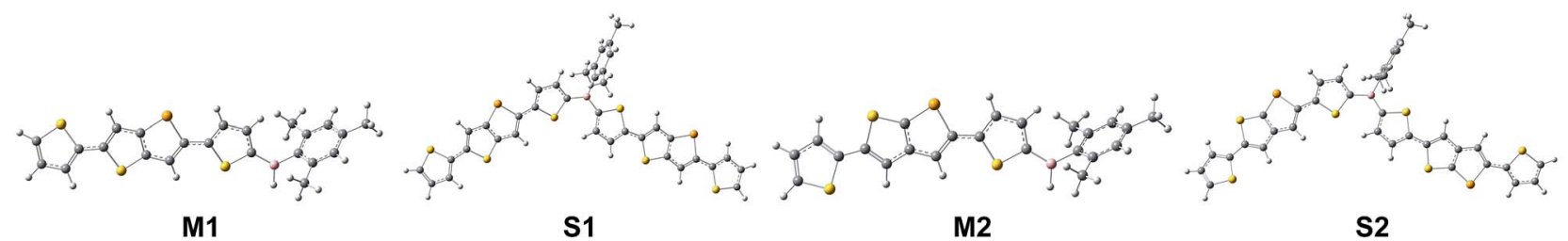

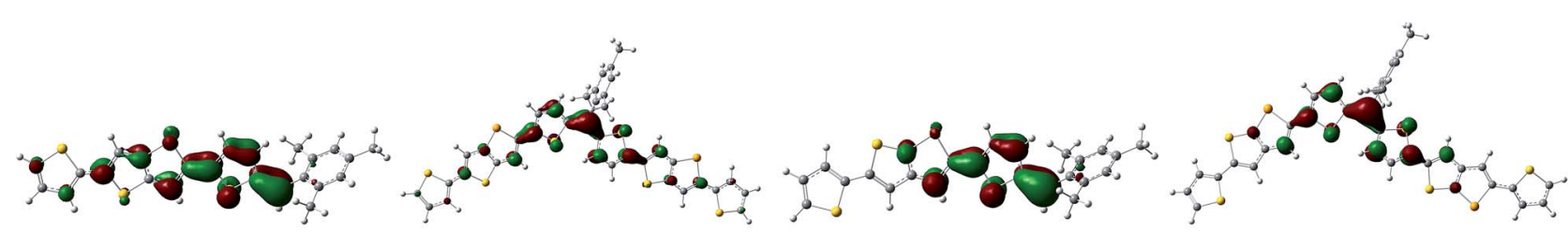

LUMO
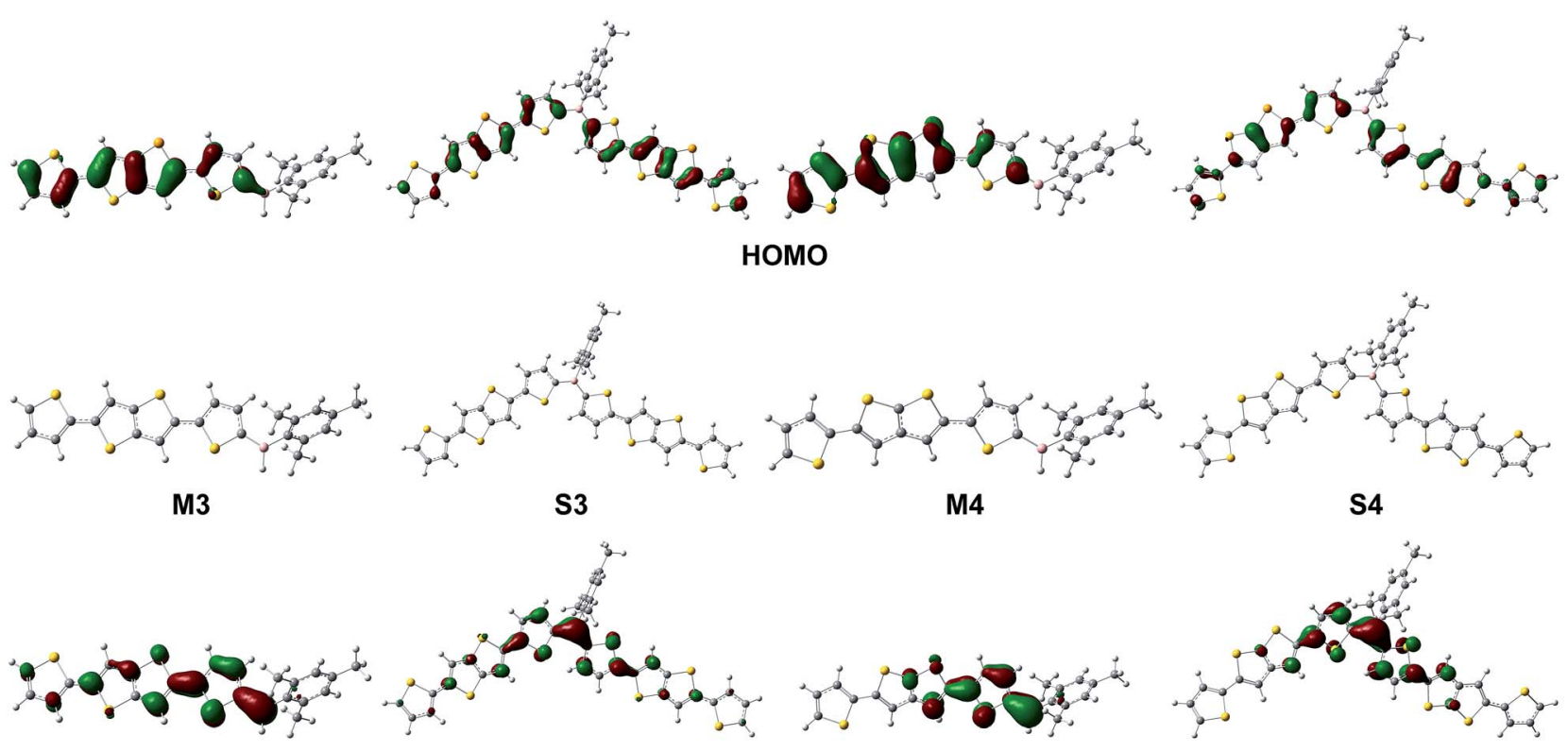

LUMO

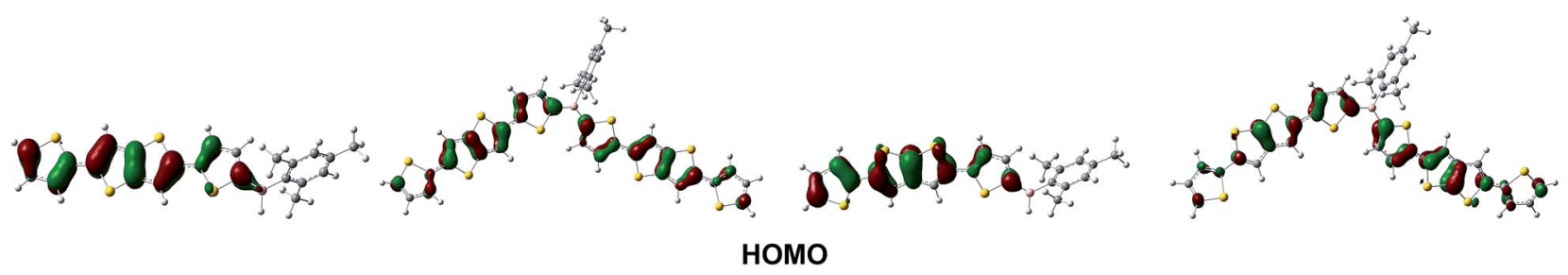

Fig. 5 FMOs (isosurface value $=0.04 \mathrm{au}$ ) of monomers M1-M4 and segments S1-S4 at (PCM:THF)B3LYP/6-31G(d) level.

the trend well aligns with those obtained from the onset of UVVis absorption spectra, demonstrating the smaller band gaps for $\mathbf{S 1}$ and $\mathbf{S} 3$ with Se than their corresponding $\mathbf{S} 2$ and $\mathbf{S 4}$ having $\mathrm{S}$ atoms.

Orbital composition analysis provided the highest LUMO orbital composition of $22.0 \%$ for boron atom of $\mathbf{S 4}$ and the lowest one for boron atom of $\mathbf{S 1}$ with $\mathbf{1 7 . 0 \%}$ orbital composition supporting the experimentally obtained fluoride quenching efficiencies. The larger the LUMO orbital composition on boron atom, the higher the sensitivity of boron atom toward Lewis base.

The estimated UV-Vis absorption spectra of S1-S4 and vertical excitation energies are provided in Fig. $\mathrm{S} 13 \dagger$ and
Table 2, respectively. The computed spectral properties are matching well with the experimentally observed values. The $\lambda_{\max }$ values of compounds arise from the HOMO to LUMO transitions pointing out the fact that the low energy transitions emerge from HOMO $\rightarrow$ LUMO. Emission spectra of the polymer segments were predicted by performing the calculations on the optimized excited state geometries with solvent effect (CPCM:THF). The obtained emission spectra are illustrated in Fig. S14. $\dagger$ In all segments (S1-S4), the emission predominantly originates from LUMO $\rightarrow$ HOMO transition, well in alignment with the experimental outcome (Table S1†). Fluoride attachment on the electron deficient boron atom (S1-F-S4-F) switches the planar geometry of boron to tetrahedral structure. While the 
Table 2 Excited state electronic transitions at (CPCM:THF)-CAM-TD-B3LYP/6-311++G(d,p)//B3LYP/6-31G(d) level

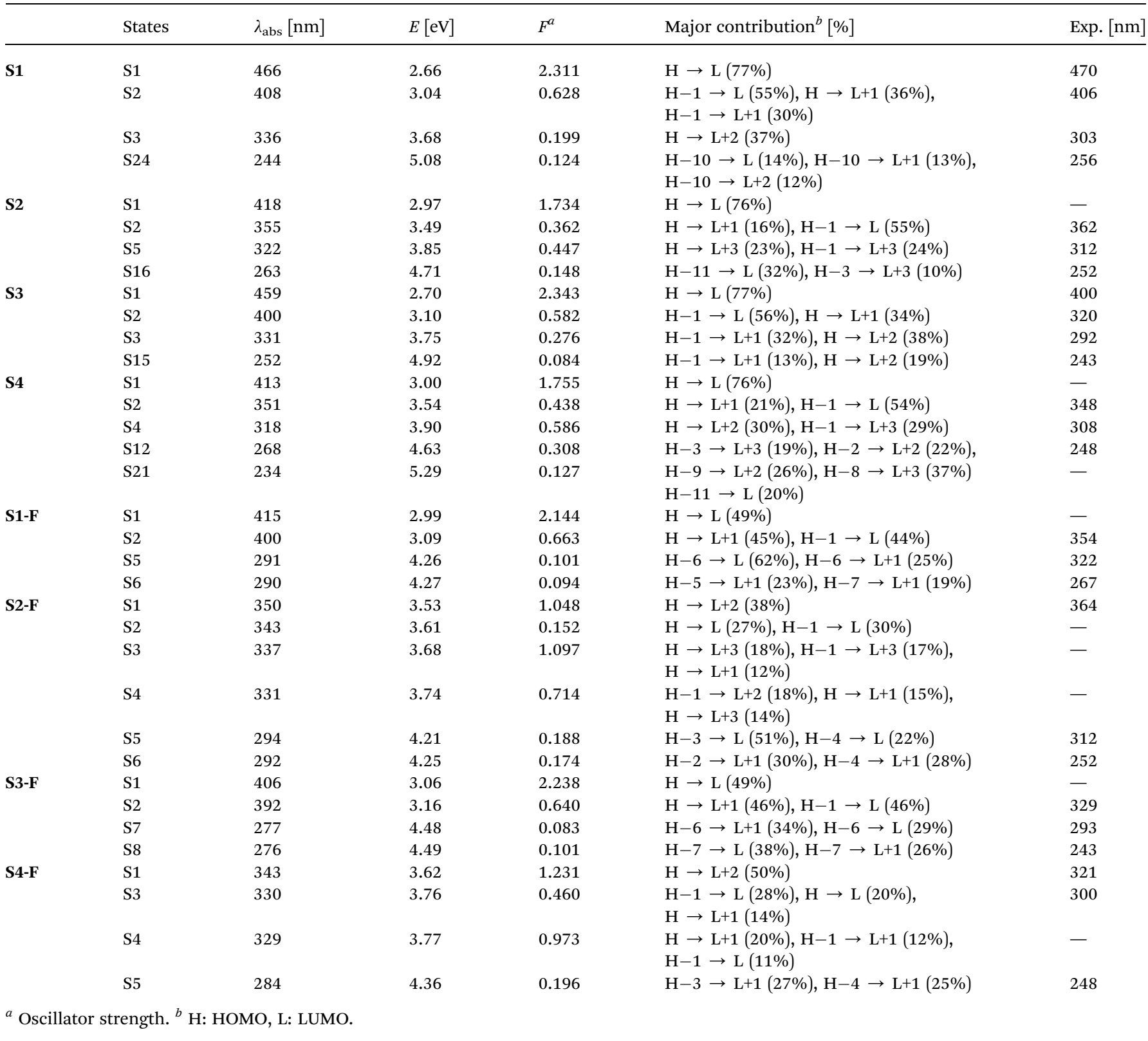

HOMOs and LUMOs were observed on the whole molecule, excluding mesityl boron units in S1-F and S3-F, HOMOs were speaded over the system up to cross-conjugated rings and LUMOs were localized on one of the terminal thiophene separated by cross-conjugated systems in S2-F and S4-F (Fig. S12 $\dagger$ ). This results in the interruption of charge transfer. As a consequent, it gives rise to a blue shift in the predicted absorption spectra by $51-70 \mathrm{~nm}$, which is matching well with the results recorded in the fluoride sensing investigations (Table 2).

\section{Conclusions}

Synthesis of new four $\mathrm{D}-\pi-\mathrm{A}$ polymers was realized, which possess fused bicyclic aromatic rings thieno[3,2- $b]$ thiophene, selenopheno[3,2- $b]$ thiophene, thieno[2,3- $b]$ thiophene and selenopheno[2,3- $b]$ thiophene as donors and mesitylboron as an acceptor connected through a thiophene $\pi$-spacer. Their properties were investigated optically, electrochemically and as fluoride ion sensors, comparing their structures and interactions of $\mathrm{S}$ and Se atoms with boron. As selenium atoms improve the conjugation and facilitate charge-transfer processes due to their more polarizable and less electronegative properties, polymer P1, having better optical properties compared to P3, exhibited a broader absorption band with a larger red shift emission band.

Moreover, P1 exhibited the longest emission wavelength, and thus the largest Stokes shift among the four organoboronbased polymers. Quantum efficiencies of the polymers were 
obtained to be in the range of $5-18 \%$. DFT studies shed light on their electronic structures and frontier molecular orbitals, which supported the experimental outcome. CAM-TD-B3LYP calculations provided vertical excitations from HOMO to LUMO with energies varying from 2.66 to $3.00 \mathrm{eV}$. Fluoride sensing properties of these polymers P1-P4 were investigated through absorption and emission measurements, owing to the high Lewis acidity of the boron centres to coordinate fluoride anions. The enhancement of strong sensitivity with P4 was detected in comparison to the other polymers P1-P3, which was interpreted to be due to the presence of less polarizable sulfur atom compare with selenium and its cross-conjugated structure. Upon addition of TBAF as a fluoride ion source, P1-P4 exhibited a "turn off" sensor properties, observed by a colour change of the solution from yellow to completely colourless. Thus, the present polymers can be used as fluorescent or colorimetric fluoride anion sensors. On the basis of the optical and electrochemical studies, these polymers can be promising candidates for the large area device fabrication as functional materials.

\section{Experimental}

All reagents were used as received from commercial sources without further purification. Tetrahydrofuran (THF) and diethyl ether $\left(\mathrm{Et}_{2} \mathrm{O}\right)$ were dried over sodium in the presence of benzophenone. All chemical reactions were performed under $\mathrm{N}_{2}$ atmosphere. 2,5-Dibromoselenopheno[3,2-b]thiophene (1) ${ }^{3 b, 16,32,33} 2,5$-dibromoselenopheno[2,3-b]thiophene (2), ${ }^{17,18,32}$ 2,5-dibromothieno[3,2-b]thiophene (3), ${ }^{\mathbf{1 6}, 34}$ 2,5-dibromothieno [2,3- $b]$ thiophene $(\mathbf{4}),{ }^{\mathbf{1 6}, \mathbf{3 4 b}} \quad 4,4,5,5$-tetramethyl-2-(thiophen-2-yl)$[1,3,2]$ dioxaborolane $^{35}$ and mesityldimethoxyborane ${ }^{36}$ were synthesized according to published procedures. ${ }^{1} \mathrm{H}$ and ${ }^{13} \mathrm{C}$ NMR spectra were recorded on a Varian model NMR $(500 \mathrm{MHz})$. Proton and carbon chemical shifts are reported in ppm downfield from tetramethylsilane (TMS). UV-Vis measurements were studied on HITACHI U-0080D. Mass spectra were recorded on Bruker MICROTOFQ and Thermo LCQ-Deca ion trap mass instruments. CH-Instruments Model 400A was used as a potentiostat for the CV studies. Cyclic voltammetry was performed on a glassy carbon disk electrode coated with a polymer thin film was used as the working electrode, a platinum wire as the counter electrode and an $\mathrm{Ag}$ wire as the reference electrode. Tetrabutylammonium hexafluorophosphate $\left(\mathrm{Bu}_{4} \mathrm{NPF}_{6}\right)(0.1 \mathrm{M})$ in acetonitrile, saturated with nitrogen, was used as the supporting electrolyte. A ferrocene internal standard was used to calibrate the results. The molar mass and molar mass distribution of the polymers were determined using gel permeation chromatography, equipped with Perkin-Elmer 200 GPC high pressure pump, injector, THF columns (guard column + Styragel HR 2 + Styragel HR 3 + Styragel HR 4E + Styragel HR 5E), Wyatt Optilab differential refractive index detector $(654 \mathrm{~nm})$ and Dawn Heleos multi angle light-scattering detector. The mobile phase was THF (flow rate: $0.7 \mathrm{~mL} \mathrm{~min}^{-1}$ ). Measurements were conducted at $25{ }^{\circ} \mathrm{C}$. Polymer concentrations were in the range of $0.5-2.0 \mathrm{mg} \mathrm{mL}{ }^{-1}$ and all the samples were filtered through $0.2 \mu \mathrm{m}$ filter prior to use. Thermal gravimetric analyses
(TGA) of the polymers were performed by EXSTAR-SII TG/ DTA7300 thermal gravimetry-differential thermal analysis (TGDTA) under dynamic argon atmosphere. Temperature calibration of the instrument was conducted according to indium melting point and enthalpy.

\section{2,5-Di(thiophen-2-yl)selenopheno[3,2-b]thiophene (5)}

In a Schlenk tube, a mixture of 2-(thiophen-2-yl)-4,4,5,5tetramethyl-1,3,2-dioxaborolane (687 mg, $3.27 \mathrm{mmol}$ ), 2,5dibromoselenopheno[3,2- $b]$ thiophene (1) (451 $\mathrm{mg}, 1.30 \mathrm{mmol})$ and $2 \mathrm{M}$ aqueous $\mathrm{K}_{2} \mathrm{CO}_{3}(2 \mathrm{~mL})$ in a stirred THF $(30 \mathrm{~mL})$ was flushed with $\mathrm{N}_{2}$ for $15 \mathrm{~min}$. Then, to this mixture was added $\mathrm{Pd}\left(\mathrm{PPh}_{3}\right)_{2} \mathrm{Cl}_{2}(69.0 \mathrm{mg}, 5 \% \mathrm{mmol})$ as catalyst and it was refluxed with vigorous stirring for $60 \mathrm{~h}$. The excess solvent was distilled and the compound was extracted with dichloromethane (DCM) $(3 \times 20 \mathrm{~mL})$. The organic phase was washed with water, dried over anhydrous $\mathrm{MgSO}_{4}$ and solvent was evaporated. The residue was purified by column chromatography using $n$-hexane/DCM ( $\left.5: 1, R_{\mathrm{f}}=0.78\right)$ to obtain an orange solid in $55 \%(253 \mathrm{mg})$ yield. M.p. $220-221{ }^{\circ} \mathrm{C} ;{ }^{1} \mathrm{H}$ NMR (500 MHz, $\mathrm{CDCl}_{3}$ ): $\delta 7.45$ (s, $1 \mathrm{H}), 7.33(\mathrm{~s}, 1 \mathrm{H}), 7.24$ (d, $J=5.5 \mathrm{~Hz}, 2 \mathrm{H}), 7.21(\mathrm{~d}, J=3.5 \mathrm{~Hz}, 1 \mathrm{H})$, 7.15 (d, $J=3.5 \mathrm{~Hz}, 1 \mathrm{H}), 7.04-7.01(\mathrm{~m}, 2 \mathrm{H}) ;{ }^{13} \mathrm{C}$ NMR $(125 \mathrm{MHz}$, $\left.\mathrm{CDCl}_{3}\right): \delta 141.9,139.7,139.5,138.5,137.6,137.4,127.9,126.8$, 124.9, 124.7, 124.3, 123.8, 118.9, 117.9. MS (m/z): $[\mathrm{M}+2]^{+}$calcd for $\mathrm{C}_{14} \mathrm{H}_{8} \mathrm{~S}_{3} \mathrm{Se}, 351.89$; found, 353.10.

Following the same procedure of $\mathbf{5}$, compounds 6-8 were prepared.

\section{2,5-Di(thiophen-2-yl)selenopheno[2,3-b]thiophene (6)}

Compound 2 (736 mg, $2.10 \mathrm{mmol}$ ) was reacted with 2(thiophen-2-yl)-4,4,5,5-tetramethyl-1,3,2-dioxaborolane (942 mg $4.48 \mathrm{mmol})$ in the presence of $2 \mathrm{M}$ aqueous $\mathrm{K}_{2} \mathrm{CO}_{3}(10.7 \mathrm{~mL})$ and $\mathrm{PdCl}_{2}\left(\mathrm{PPh}_{3}\right)_{2}(212 \mathrm{mg}, 5 \% \mathrm{~mol})$ in THF (35 mL). The residue was purified by column chromatography using $n$-hexane/DCM $(5: 1$, $\left.R_{\mathrm{f}}=0.70\right)$ affording a pale yellow solid in $48 \%$ (357 $\left.\mathrm{mg}\right)$ yield. M.p. $169-170{ }^{\circ} \mathrm{C} ;{ }^{1} \mathrm{H}$ NMR $\left(500 \mathrm{MHz}, \mathrm{CDCl}_{3}\right): \delta 7.40(\mathrm{dd}, J$ $=5.0$ and $1.0 \mathrm{~Hz}, 1 \mathrm{H}), 7.38(\mathrm{dd}, J=3.8$ and $2.5 \mathrm{~Hz}, 1 \mathrm{H}), 7.32(\mathrm{~s}$, $1 \mathrm{H}), 7.27(\mathrm{~d}, J=1.0 \mathrm{~Hz}, 1 \mathrm{H}), 7.26(\mathrm{~d}, J=1.5 \mathrm{~Hz}, 1 \mathrm{H}), 7.21(\mathrm{dd}, J=$ 3.8 and $1.2 \mathrm{~Hz}, 1 \mathrm{H}$ ), 7.10 (dd, $J=5.2$ and $3.8 \mathrm{~Hz}, 1 \mathrm{H}), 7.04$ (dd, $J$ $=5.2$ and $3.8 \mathrm{~Hz}, 1 \mathrm{H}) ;{ }^{13} \mathrm{C}$ NMR $\left(125 \mathrm{MHz}, \mathrm{CDCl}_{3}\right): \delta 148.8$, 140.9 , 136.8, 136.3, 135.7, 130.6, 127.8, 127.4, 127.2, 126.7, 125.0, 124.3, 118.5, 101.8. MS $(\mathrm{m} / z):[\mathrm{M}+1]^{+}$calcd for $\mathrm{C}_{14} \mathrm{H}_{8} \mathrm{~S}_{3} \mathrm{Se}$, 351.89; found, 352.00 .

\section{2,5-Di(thiophen-2-yl)thieno[3,2-b]thiophene $(7)^{37}$}

Compound 3 (585 mg $1.90 \mathrm{mmol}$ ) was treated with 2-(thiophen2-yl)-4,4,5,5-tetramethyl-1,3,2-dioxaborolane (866 mg, 4.12 $\mathrm{mmol})$ in the presence of $2 \mathrm{M}$ aqueous $\mathrm{K}_{2} \mathrm{CO}_{3}(10 \mathrm{~mL})$ and $\mathrm{PdCl}_{2}\left(\mathrm{PPh}_{3}\right)_{2}(140 \mathrm{mg}, 5 \% \mathrm{~mol})$ in THF $(40 \mathrm{~mL})$. The residue was purified by column chromatography using $n$-hexane/DCM $(5: 1$, $\left.R_{\mathrm{f}}=0.75\right)$ furnishing a yellow solid in $72 \%(433 \mathrm{mg})$ yield. M.p. 255-256 ${ }^{\circ} \mathrm{C} ;{ }^{1} \mathrm{H}$ NMR $\left(500 \mathrm{MHz}, \mathrm{CDCl}_{3}\right): \delta 7.46(\mathrm{dd}, J=3.5$ and $1.2 \mathrm{~Hz}, 2 \mathrm{H}$ ), 7.39 (dd, $J=5.2$ and $1.2 \mathrm{~Hz}, 2 \mathrm{H}$ ), 7.28 (s, 2H), 7.11 $(\mathrm{dd}, J=5.2$ and $3.5 \mathrm{~Hz}, 2 \mathrm{H}) ;{ }^{13} \mathrm{C} \mathrm{NMR}\left(125 \mathrm{MHz} \mathrm{CDCl}_{3}\right): \delta 147.3$, $140.7,137.5$, 135.5, 133.6, 128.0, 126.6, 125.2, 124.4, 116.2. 


\section{2,5-Di(thiophen-2-yl)thieno[2,3-b]thiophene (8)}

Compound 4 (414 mg $1.40 \mathrm{mmol}$ ) was reacted with 2-(thiophen2-yl)-4,4,5,5-tetramethyl-1,3,2-dioxaborolane $(650 \mathrm{mg}, \quad 3.10$ $\mathrm{mmol})$ in the presence of $2 \mathrm{M}$ aqueous $\mathrm{K}_{2} \mathrm{CO}_{3}(7 \mathrm{~mL})$ and $\mathrm{PdCl}_{2}\left(\mathrm{PPh}_{3}\right)_{2}(100 \mathrm{mg}, 5 \% \mathrm{~mol})$ in THF $(40 \mathrm{~mL})$ following the above procedure. The residue was purified by column chromatography using $n$-hexane/DCM $\left(5: 1, R_{\mathrm{f}}=0.68\right)$ providing a yellowish orange solid in $40 \%(166 \mathrm{mg})$ yield. M.p. $195-196{ }^{\circ} \mathrm{C}$; ${ }^{1} \mathrm{H}$ NMR (500 MHz, $\mathrm{CDCl}_{3}$ ): $\delta 7.27(\mathrm{~s}, 2 \mathrm{H}), 7.25$ (dd, $J=5.2$ and $1.0 \mathrm{~Hz}, 2 \mathrm{H}$ ), 7.21 (dd, $J=3.5$ and $1.0 \mathrm{~Hz}, 2 \mathrm{H}), 7.04$ (dd, $J=5.2$ and $3.5 \mathrm{~Hz}, 2 \mathrm{H}) ;{ }^{13} \mathrm{C}$ NMR $\left(125 \mathrm{MHz}, \mathrm{CDCl}_{3}\right)$ : $\delta$ 146.9, 139.8, 137.3, 134.9, 127.8, 124.6, 124.3, 123.7, 116.3.

\section{General method for the syntheses of the polymers P1-P4}

To a solution of 2,5-di(thiophen-2-yl)selenopheno[3,2- $b]$ thiophene (5) (272 mg, $770 \mu \mathrm{mol})$ in $60 \mathrm{~mL}$ of dry THF was added $1.06 \mathrm{~mL} n$-BuLi (1.6 M, $1.70 \mathrm{mmol}$ ) dropwise at $-78{ }^{\circ} \mathrm{C}$ under nitrogen atmosphere. After $1 \mathrm{~h}$, the temperature was warmed up to room temperature. Stirring was then continued for another $1 \mathrm{~h}$. The mixture was then cooled down to $-78{ }^{\circ} \mathrm{C}$ and $\mathrm{MesB}(\mathrm{OMe})_{2}(168 \mu \mathrm{L}, 900 \mu \mathrm{mol})$ was added and the solution was allowed to warm up to room temperature and the mixture was stirred for 3 days. After removal of the solvent under reduced pressure, the crude product was dissolved in a minimum amount of THF and precipitated in $n$-hexane. The precipitate was filtered, washed repeatedly with $n$-hexane and dried under vacuum to afford $\mathbf{P 1}$ as a reddish-orange solid in yield of 50\% (198 mg). $M_{\mathrm{n}}=97.9 \mathrm{kDa}, M_{\mathrm{w}}=110.0 \mathrm{kDa}, M_{\mathrm{w}} / M_{\mathrm{n}}(\mathrm{\Xi})=1.12$.

\section{Synthesis of P2}

Polymerization of compound $6(257 \mathrm{mg}, 730 \mu \mathrm{mol})$, with $\mathrm{MesB}(\mathrm{OMe})_{2}(125 \mu \mathrm{L}, 800 \mu \mathrm{mol})$ in the presence of $n$-BuLi (960 $\mu \mathrm{L}, 1.6 \mathrm{M}, 1.50 \mathrm{mmol}$ ) in $40 \mathrm{~mL}$ of dry THF gave $\mathbf{P} 2$ as a yellow solid in $40 \%$ yield $\left(150 \mathrm{mg}\right.$ ). $M_{\mathrm{n}}=11.2 \mathrm{kDa}, M_{\mathrm{w}}=28.7 \mathrm{kDa}, M_{\mathrm{w}} /$ $M_{\mathrm{n}}(\mathrm{D})=2.55$.

\section{Synthesis of P3}

Polymerization of compound $7(273 \mathrm{mg} 900 \mu \mathrm{mol})$ with $\operatorname{MesB}(\mathrm{OMe})_{2}(147 \mu \mathrm{L}, 1.00 \mathrm{mmol})$ in the presence of $n$-BuLi (1.17 $\mathrm{mL}, 1.6 \mathrm{M}, 1.88 \mathrm{mmol}$ ) in $40 \mathrm{~mL}$ of dry THF furnished $\mathbf{P} 3$ as a reddish-brown solid in yield of $39 \%(165 \mathrm{mg}) . M_{\mathrm{n}}=40.5 \mathrm{kDa}$, $M_{\mathrm{w}}=55.6 \mathrm{kDa}, M_{\mathrm{w}} / M_{\mathrm{n}}(\mathrm{Ð})=1.37$.

\section{Synthesis of $\mathbf{P 4}$}

Polymerization of compound $8(240 \mathrm{mg}, 800 \mu \mathrm{mol})$ with $\mathrm{MesB}(\mathrm{OMe})_{2}(185 \mu \mathrm{L}, 900 \mu \mathrm{mol})$ in the presence of $n$-BuLi $(1.00$ $\mathrm{mL}, 1.6 \mathrm{M}, 1.60 \mathrm{mmol}$ ), in $40 \mathrm{~mL}$ of dry THF afforded $\mathbf{P 4}$ as an orange solid in $44 \%$ yield (160 mg). $M_{\mathrm{n}}=40.7 \mathrm{kDa}, M_{\mathrm{w}}=62.7$ $\mathrm{kDa}, M_{\mathrm{w}} / M_{\mathrm{n}}(Đ)=1.54$.

\section{Acknowledgements}

G. T. and M. E. C. thank the Scientific and Technological Research Council of Turkey (TUBITAK) for Postdoctoral Research Fellowships BIDEB 2218 and 2216 programs, respectively. We thank Prof. M. S. Eroglu for Light Scattering measurements. We are indebted to National Center for High Performance Computing (UYBHM) (tvddvb) and the HighPerformance-Computing (HPC) Linux Cluster HorUS of University of Siegen for the computer time provided. Unsped Global Logistic is gratefully acknowledged for financial support.

\section{References}

1 (a) Y. M. Kim, E. Lim, I. N. Kang, B. J. Jung, J. Lee, B. W. Koo, L. M. Do and H. K. Shim, Macromolecules, 2006, 39, 40814085; (b) J. Hollinger, D. Gao and D. S. Seferos, Isr. J. Chem., 2014, 54, 440-453; (c) A. Patra, M. Bendikov and S. Chand, Acc. Chem. Res., 2014, 47, 1465-1474.

2 (a) T. Yamamoto and K. Takimiya, J. Am. Chem. Soc., 2007, 129, 2224-2225; (b) H. Ebata, E. Miyazaki, T. Yamamoto and K. Takimiya, Org. Lett., 2007, 9, 4499-4502.

3 (a) A. M. Ballantyne, L. Chen, J. Nelson, D. D. C. Bradley, Y. Astuti, A. Maurano, C. G. Shuttle, J. R. Durrant, M. Heeney, W. Duffy and I. McCulloch, Adv. Mater., 2007, 19, 4544-4547; (b) S. P. Mishra, A. E. Javier, R. Zhang, J. Liu, J. A. Belot, I. Osaka and R. D. McCullough, J. Mater. Chem., 2011, 21, 1551-1561; (c) K. Takimiya, Y. Kunugi, Y. Konda, H. Ebata, Y. Toyoshima and T. Otsubo, J. Am. Chem. Soc., 2006, 128, 3044-3050; (d) K. Takimiya, Y. Konda, H. Ebata, N. Niihara and T. Otsubo, J. Org. Chem., 2005, 70, 10569-10571; (e) Y. A. Getmanenko, P. Tongwa, T. V. Timofeeva and S. R. Marder, Org. Lett., 2010, 12, 2136-2139.

4 (a) M. R. Bryce, J. Mater. Chem., 1995, 5, 1481-1496; (b) E. Ertas, İ. Demirtas and T. Ozturk, Beilstein J. Org. Chem., 2015, 11, 403-415.

5 (a) Y. Kunugi, K. Takimiya, Y. Toyoshima, K. Yamashita, Y. Aso and T. Otsubo, J. Mater. Chem., 2004, 14, 1367-1369; (b) D. J. Crouch, P. J. Skabara, J. E. Lohr, J. J. W. McDouall, M. Heeney, I. McCulloch, D. Sparrowe, M. Shkunov, S. J. Coles, P. N. Horton and M. B. Hursthouse, Chem. Mater., 2005, 17, 6567-6568.

6 (a) S. S. Zade and M. Bendikov, Org. Lett., 2006, 8, 5243-5246; (b) U. Salzner, J. B. Lagowski, P. G. Pickup and R. A. Poirier, Synth. Met., 1998, 96, 177-189.

7 H. Pang, P. J. Skabara, S. Gordeyev and J. J. W. McDouall, Chem. Mater., 2007, 19, 301-307.

8 A. Patra, Y. H. Wijsboom, S. S. Zade, M. Li, Y. Sheynin, G. Leitus and M. Bendikov, J. Am. Chem. Soc., 2008, 130, 6734-6736.

9 (a) M. E. Cinar and T. Ozturk, in Thiophenes, ed. J. A. Joule, Springer-Verlag, Berlin Heidelberg, 2014, pp. 161-202; (b) M. E. Cinar and T. Ozturk, Chem. Rev., 2015, 115, 30363140; (c) S. T. Cankaya, A. Capan, M. E. Cinar, E. Akin, S. Topal and T. Ozturk, J. Sulfur Chem., 2013, 34, 638-645; (d) A. Buyruk, M. E. Cinar, M. S. Eroglu and T. Ozturk, ChemistrySelect, 2016, 1, 3028-3032.

10 (a) W.-H. Lee, S. K. Son, K. Kim, S. K. Lee, W. S. Shin, S.-J. Moon and I.-N. Kang, Macromolecules, 2012, 45, 13031312; (b) M. Heeney, W. Zhang, D. J. Crouch, M. L. Chabinyc, S. Gordeyev, R. Hamilton, S. J. Higgins, 
I. McCulloch, P. J. Skabara, D. Sparrowe and S. Tierney, Chem. Commun., 2007, 47, 5061-5063.

11 (a) D. S. Chung, H. Kong, W. M. Yun, H. Cha, H.-K. Shim, Y.-H. Kim and C. E. Park, Org. Electron., 2010, 11, 899-904; (b) S. Das and S. S. Zade, Chem. Commun., 2010, 46, 11681170; (c) S. Haid, A. Mishra, C. Uhrich, M. Pfeiffer and P. Bauerle, Chem. Mater., 2011, 23, 4435-4444; (d) S. Das, P. B. Pati and S. S. Zade, Macromolecules, 2012, 45, 54105417.

12 (a) Y. J. Cheng, S. H. Yang and C. S. Hsu, Chem. Rev., 2009, 109, 5868-5923; (b) G. Turkoglu, M. E. Cinar, A. Buyruk, E. Tekin, S. P. Mucur, K. Kaya and T. Ozturk, J. Mater. Chem. C, 2016, 4, 6045-6053; (c) E. B. Sevinis, C. Sahin, M. E. Cinar, M. S. Eroglu and T. Ozturk, Polym. Eng. Sci., 2016, 56, 1390-1398; (d) E. Sezer, I. Osken, M. E. Cinar, O. Demirel, B. Ustamehmetoğlu and T. Ozturk, Electrochim. Acta, 2016, 222, 1592-1603.

13 (a) F. Jäkle, Chem. Rev., 2010, 110, 3985-4022; (b) P. Chen and F. Jäkle, J. Am. Chem. Soc., 2011, 133, 20142-20145; (c) A. M. Priegert, B. W. Rawe, S. C. Serin and D. P. Gates, Chem. Soc. Rev., 2016, 45, 922-953; (d) Y. Ren and F. Jäkle, Dalton Trans., 2016, 45, 13996-14007.

14 (a) N. Matsumi, K. Naka and Y. Chujo, J. Am. Chem. Soc., 1998, 120, 10776-10777; (b) J. F. Mike and J. L. Lutkenhaus, J. Polym. Sci., Part B: Polym. Phys., 2013, 51, 468-480; (c) J. Winsberg, T. Hagemann, S. Muench, C. Friebe, B. Häupler, T. Janoschka, S. Morgenstern, M. D. Hager and U. S. Schubert, Chem. Mater., 2016, 28, 3401-3405; (d) X. Yin, F. Guo, R. A. Lalancette and F. Jäkle, Macromolecules, 2016, 49, 537-546.

15 (a) G. Zhou, M. Baumgarten and K. Mullen, J. Am. Chem. Soc., 2008, 130, 12477-12484; (b) H. Li and F. Jäkle, Macromol. Rapid Commun., 2010, 31, 915-920; (c) Z. M. Hudson and S. Wang, Acc. Chem. Res., 2009, 42, 1584-1596; (d) S. Yamaguchi, S. Akiyama and K. Tamao, J. Am. Chem. Soc., 2001, 123, 11372-11375; (e) C. R. Wade, A. E. J. Broomsgrove, S. Aldridge and F. P. Gabbaï, Chem. Rev., 2010, 110, 3958-3984; (f) H. Zhao, L. A. Leamer and F. P. Gabbaï, Dalton Trans., 2013, 42, 8164-8178; $(g)$ F. Cheng, E. M. Bonder and F. Jäkle, J. Am. Chem. Soc., 2013, 135, 17286-17289; (h) S.-B. Zhao, P. Wucher, Z. M. Hudson, T. M. McCormik, X.-Y. Liu, S. Wang, X.-D. Feng and Z.-H. Lu, Organometallics, 2008, 27, 64466456; ( $i$ ) S. K. Mellerup, Y.-L. Rao, H. Amarne and S. Wang, Org. Lett., 2016, 18, 4436-4439; (j) Y. Hu, Z. Zhao, X. Bai, X. Yuan, X. Zhang and T. Masuda, RSC Adv., 2014, 4, 55179-55186; (k) H. Li and F. Jäkle, Angew. Chem., Int. Ed., 2009, 48, 2313-2316.

16 M. Heeney, C. Bailey, K. Genevicius, M. Giles, M. Shkunov, D. Sparrowe, S. Tierney, W. Zhang and I. McCulloch, Proc. SPIE, 2005, 5940, 1-9.

17 S. Yasuike, J. Kurita and T. Tsuchiya, Heterocycles, 1997, 45, 1891-1894.

18 V. P. Litvinov, Y. L. Gol'dfarb and I. P. Konyaeva, Izv. Akad. Nauk SSSR, Ser. Khim., 1980, 2, 372-377.

19 (a) H. Kong, Y. K. Jung, N. S. Cho, I.-N. Kang, J.-H. Park, S. Cho and H.-K. Shim, Chem. Mater., 2009, 21, 2650-2660; (b) M. D. Curtis, J. Cao and J. W. Kampf, J. Am. Chem. Soc., 2004, 126, 4318-4328; (c) E. G. Kim, V. Coropceanu, N. E. Gruhn, R. S. Sanchez-Carrera, R. Snoeberger, A. J. Matzger and J. L. Bredas, J. Am. Chem. Soc., 2007, 129, 13072-13081.

20 (a) S. Yamaguchi, S. Akiyama and K. Tamao, J. Organomet. Chem., 2002, 652, 3-9; (b) P. Chen and F. Jäkle, J. Am. Chem. Soc., 2011, 133, 20142-20145; (c) P. Chen, X. Yin, N. Baser-Kirazli and F. Jäkle, Angew. Chem., Int. Ed., 2015, 54, 10768-10772.

21 (a) T. W. Hudnall, C.-W. Chiu and F. P. Gabbaï, Acc. Chem. Res., 2009, 42, 388-397; (b) T. Agou, J. Kobayashi and T. Kawashima, Chem.-Eur. J., 2007, 13, 8051-8060; (c) S. Miyasaka, J. Kobayashi and T. Kawashima, Tetrahedron Lett., 2009, 50, 3467-3469; (d) Z. Zhang, R. M. Edkins, J. Nitsch, K. Fucke, A. Eichhorn, A. Steffen, Y. Wang and T. B. Marder, Chem.-Eur. J., 2015, 21, 177-190; (e) D. R. Levine, M. A. Siegler and J. D. Tovar, J. Am. Chem. Soc., 2014, 136, 7132-7139; (f) H. Shia, J. Yanga, X. Donga, L. Fanga, C. Donga and M. M. F. Choib, Synth. Met., 2013, 179, 42-48; (g) Z.-Q. Liu, M. Shi, F.-Y. Li, Q. Fang, Z.-H. Chen, T. Yi and C.-H. Huang, Org. Lett., 2005, 7, 5481-5484.

22 (a) M. Miyata and Y. Chujo, Polym. J., 2002, 34, 967-969; (b) A. Sundararaman, M. Victor, R. Varughese and F. Jäkle, J. Am. Chem. Soc., 2005, 127, 13748-13749; (c) V. D. B. Bonifacio, J. Morgado and U. Scherf, J. Polym. Sci., Part A: Polym. Chem., 2008, 46, 2878-2883; (d) W. Liu, M. Pink and D. Lee, J. Am. Chem. Soc., 2009, 131, 87038707; (e) K. Parab, K. Venkatasubbaiah and F. Jäkle, J. Am. Chem. Soc., 2006, 128, 12879-12885; $(f)$ K. Parab and F. Jäkle, Macromolecules, 2009, 42, 4002-4007; $(g)$ F. Guo, X. Yin, F. Pammer, F. Cheng, D. Fernandez, R. A. Lalancette and F. Jäkle, Macromolecules, 2014, 47, 7831-7841.

23 M. J. Frisch, G. W. Trucks, H. B. Schlegel, G. E. Scuseria, M. A. Robb, J. R. Cheeseman, G. Scalmani, V. Barone, B. Mennucci, G. A. Petersson, H. Nakatsuji, M. Caricato, X. Li, H. P. Hratchian, A. F. Izmaylov, J. Bloino, G. Zheng, J. L. Sonnenberg, M. Hada, M. Ehara, K. Toyota, R. Fukuda, J. Hasegawa, M. Ishida, T. Nakajima, Y. Honda, O. Kitao, H. Nakai, T. Vreven, J. A. Montgomery Jr, J. E. Peralta, F. Ogliaro, M. Bearpark, J. J. Heyd, E. Brothers, K. N. Kudin, V. N. Staroverov, R. Kobayashi, J. Normand, K. Raghavachari, A. Rendell, J. C. Burant, S. S. Iyengar, J. Tomasi, M. Cossi, N. Rega, J. M. Millam, M. Klene, J. E. Knox, J. B. Cross, V. Bakken, C. Adamo, J. Jaramillo, R. Gomperts, R. E. Stratmann, O. Yazyev, A. J. Austin, R. Cammi, C. Pomelli, J. W. Ochterski, R. L. Martin, K. Morokuma, V. G. Zakrzewski, G. A. Voth, P. Salvador, J. J. Dannenberg, S. Dapprich, A. D. Daniels, Ö. Farkas, J. B. Foresman, J. V. Ortiz, J. Cioslowski and D. J. Fox, Gaussian 09, Gaussian, Inc., Wallingford CT, 2010. 24 (a) A. D. Becke, J. Chem. Phys., 1993, 98, 1372-1377; (b) A. D. Becke, J. Chem. Phys., 1993, 98, 5648-5652; (c) C. Lee, W. Yang and R. G. Parr, Phys. Rev. B: Condens. Matter Mater. Phys., 1988, 37, 785-789. 
25 E. Ravindran, S. J. Ananthakrishnan, E. Varathan, V. Subramanian and N. Somanathan, J. Mater. Chem. C, 2015, 3, 4359-4371 and references 65-68 therein.

26 J. Tomasi, B. Mennucci and R. Cammi, Chem. Rev., 2005, 105, 2999-3094.

27 T. Lu and F. Chen, J. Comput. Chem., 2012, 33, 580-592.

28 (a) V. Barone and M. Cossi, J. Phys. Chem. A, 1998, 102, 19952001; (b) M. Cossi, N. Rega, G. Scalmani and V. Barone, J. Comput. Chem., 2003, 24, 669-681.

29 T. Yanai, D. P. Tew and N. C. Handy, Chem. Phys. Lett., 2004, 393, 51-57.

30 I. Borges, E. Uhl, L. Modesto-Costa, A. J. A. Aquino and H. Lischka, J. Phys. Chem. C, 2016, 120, 21818-21826.

31 N. M. O'Boyle, A. L. Tenderholt and K. M. Langner, J. Comput. Chem., 2008, 29, 839-845.

32 (a) A. F. Holleman, E. Wiberg and N. Wiberg, Lehrbuch der Anorganischen Chemie, Walter de Gruyter \& Co., Berlin, 2007; (b) H. Pang, P. J. Skabara, S. Grodeyev, J. J. W. McDouall, S. J. Coles and M. B. Hursthouse, Chem. Mater., 2007, 19, 301-307.

33 (a) M. Heeney, W. Zhang, S. Tierney and I. McCulloch, PCT Int. Appl., WO 2008077465 A2 20080703, 2008; (b)
S. P. Mishra, A. E. Javier, R. Zhang, J. Liu, J. A. Belot, I. Osaka and R. D. McCullough, J. Mater. Chem., 2011, 21, 1551-1561.

34 (a) G. H. V. Bertrand, V. K. Michaelis, T.-C. Ong, R. G. Griffin and M. Dinca, Proc. Natl. Acad. Sci. U. S. A., 2013, 110, 49234928; (b) M. Heeney, W. Zhang, S. Tierney and I. McCulloch, PCT Int. Appl., WO 2005121150A1 20051222, 2005; (c) X. Zhang, K. Markus and J. M. Adam, Macromolecules, 2004, 37, 6306-6315; (d) M. O. Ahmed, W. Pisula and S. G. Mhaisalkar, Molecules, 2012, 17, 12163-12171.

35 C. Lo and C. Hsu, J. Polym. Sci., Part A: Polym. Chem., 2011, 49, 3355-3365.

36 (a) J. B. Heilmann, M. Scheibitz, Y. Qin, A. Sundararaman, F. Jäkle, T. Kretz, M. Bolte, H.-W. Lerner, M. C. Holthausen and M. Wagner, Angew. Chem., Int. Ed., 2006, 45, 920-925; (b) M. Scheibitz, H. Li, J. Schnorr, A. S. Perucha, M. Bolte, H.-W. Lerner, F. Jäkle and M. Wagner, J. Am. Chem. Soc., 2009, 131, 16319-16329.

37 X. Zhang and A. J. Matzger, J. Org. Chem., 2003, 68, 98139815. 